\title{
High Frequency Electromagnetic Impedance Imaging for Vadose Zone and Groundwater Characterization
}

\author{
Project ID Number: 70220
}

\author{
DOE Report Number:
}

Publication Date: 6/07/2002

Lead Principal Investigator: Gregory A. Newman, Sandia National Laboratories, PO Box 5800 Albuquerque NM, 87185-0750; Phone (505) 844-8158; Email ganewma@sandia.gov

Co Investigators: Edward Nichols, $1301 \mathrm{~S} .46^{\text {th }}$ St. UCRFS Bldg. 300, Richmond, CA 94804. Phone (510) 232-7997; Email enichols1@slb.com

Co Investigators: David L. Alumbaugh, University of Wisconsin-Madison, Department of Civil and Environmental Engineering, 2258 Engineering Hall, 1415 Engineering Drive Madison, WI 53706; Phone (608) 262-3835; Email alumbaug@engr.wisc.edu

G. Michael Hoversten, Lawrence Berkeley National Laboratory, Berkeley CA 94729; Phone (510) 486-5085; Email gmhoversten@lbl.gov

\section{RESEARCH OBJECTIVE}

Accurate description of transport pathways on the gross scale, the location of contamination, and characterization of heterogeneity within the vadose zone, are now realized as vital for proper treatment, confinement and stabilization of subsurface contamination at Department of Energy (DOE) waste sites. Electromagnetic (EM) methods are ideal for these tasks since they are directly sensitive to the amount of fluid present in porous media, as well as fluid composition. At many DOE sites it is necessary to employ lower frequency $(<1 \mathrm{MHz})$ or diffusive electromagnetic fields because of the inability of ground penetrating radar (GPR) to penetrate to sufficient depths. The high frequency impedance method, which operated in the diffusive frequency range $(10 \mathrm{~Hz}$ to $1 \mathrm{MHz}$ ), as well as the low end of the spectrum employed by GPR (1MHz-10 MHz), is an ideal technique to delineate and map the aforementioned targets. The method has clearly shown the potential to provide needed information on variations in subsurface saturation due to local storage tanks and perched water zones, as well as mapping geological structures related to the subsurface hydrological properties and heterogeneity within the vadose zone.

Although it exhibits certain advantages over other EM methods, the impedance method comes with a set of assumptions and practices that can limit its potential. The first is the desire to locate receivers in the far-field of the transmitter which allows the use of magnetotelluric (MT) inversion codes to interpret the data. Unfortunately, one does not 
precisely know when one is in the far-field of the transmitter, because this depends on the geology we wish to image. The second limiting factor is the scarcity of complete 2D and $3 \mathrm{D}$ inversion schemes necessary to properly invert the data. While approximate 2D schemes are now emerging, rigorous $2 \mathrm{D}$ and $3 \mathrm{D}$ inversion codes are needed to bound the range of applicability of the approximate methods. We propose to address these problems in the following manner: (1) implement full non-linear 2D/3D inverse solutions that incorporate source coordinates and polarization characteristics, (2) use these solutions to study improvements in image resolution that can be obtained by making measurements in the near- and mid-field regimes using multiple source fields, (3) collect data at the Hanford Reservation with recently developed earth impedance measurement systems, and (4) interpret the field data with the newly developed inversion capability, as well as with additional and independent information such as well logs from boreholes. The benefit of this research to the DOE would be a combined measurement/interpretation package for non-invasive, high-resolution characterization of larger transport pathways, certain types of contamination, and heterogeneity within the vadose zone at the Hanford reservation, as well as other DOE facilities.

\section{RESEARCH PROGRESS AND IMPLICATIONS}

As of June 07, 2002, this report summarizes a portion of the work for the last twelve months of the project, in particular field work performed for the acquisition of an impedance data set using the STRATAGEM ${ }^{\mathrm{TM}}$ system. The STRATAGEM is a magnetotelluric data acquisition system used to map the subsurface conductivity in the depth range from $10 \mathrm{~m}$ to $100 \mathrm{~m}$. This system measures orthogonal electric and orthogonal magnetic fields, in the horizontal plane, using electric dipoles and magnetic induction coils. Frequencies measured are in the range from $10 \mathrm{~Hz}$ to $100 \mathrm{kHz}$, and at frequencies above $900 \mathrm{~Hz}$, a transmitter antenna is used to supplement the natural background fields. For this project, only the fields provided by the transmitter are considered.

The STRATAGEM survey was conducted during Oct. 22 through Nov.2 of 2001. The site location was the S-16 Pond Area (216-S-16P) (see Figure 1) at the DOE Hanford Reservation, having Washington State Plane coordinates of approximately $133250 \mathrm{~N}$ and 564800 E. Figure 2 is the survey layout, roughly to scale, showing the receiver stations grid, the location and orientation of the transmitter and the location of an on-site marker to be used as a location reference. Note that the $+\mathrm{X}$ and $+\mathrm{Y}$ directions are magnetic North and magnetic East, respectively. The declination of the Earth's magnetic field, at this approximate location, is $17.1^{\circ}$.

The electric fields are measured using electrodes spaced $3 \mathrm{~m}$ apart. These electrodes were metal spikes, driven into the ground approximately $25 \mathrm{~cm}$. Magnetic induction coils, approximately $1 \mathrm{~m}$ long, were used to measure the magnetic field. In the $\mathrm{X}$ direction, the stations from $\mathrm{X}=38 \mathrm{~m}$ to $\mathrm{X}=62 \mathrm{~m}$ were spaced $3 \mathrm{~m}$ apart. Outside of this range, the stations were spaced $6 \mathrm{~m}$ apart. In the $\mathrm{Y}$ direction, the stations were space $3 \mathrm{~m}$ apart.

The transmitter was located at $50 \mathrm{~m}$ North (magnetic) and $115 \mathrm{~m}$ East (magnetic) of the Southwest corner of the receiver stations grid. The magnetic dipole transmitter uses two, vertically standing loops oriented orthogonal to each other. For this survey, the loops were aligned at $45^{\circ}$ with respect to the XY coordinates of the receiver stations grid; 
thereby producing resultant transmitter dipoles parallel to the $\mathrm{XY}$ coordinates. The frequencies of the fields produced by the transmitter are listed in Table 1.

Figure 3 shows example data collected at station 23. Data shown are scalar apparent resistivity and phase and coherency.

\section{PLANNED ACTIVITES}

The acquisition of another impedance data set is planned for the summer of 2002 . Planning is still in progress, but a site may be chosen such that the target is to delineate a fluid flow in the vadose zone.

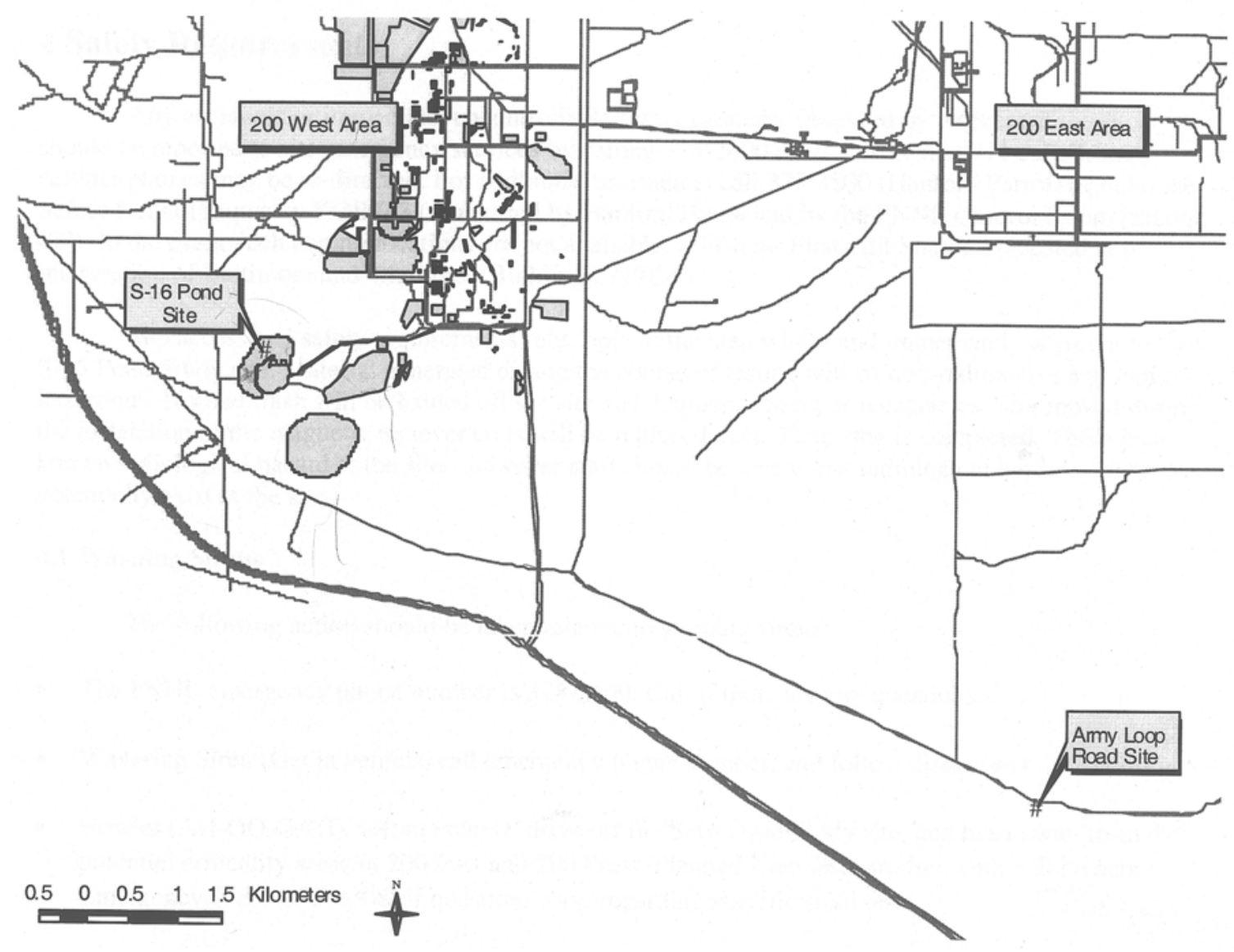

Figure 1: Location of the S-16 Pond Area at the Hanford Reservation. 


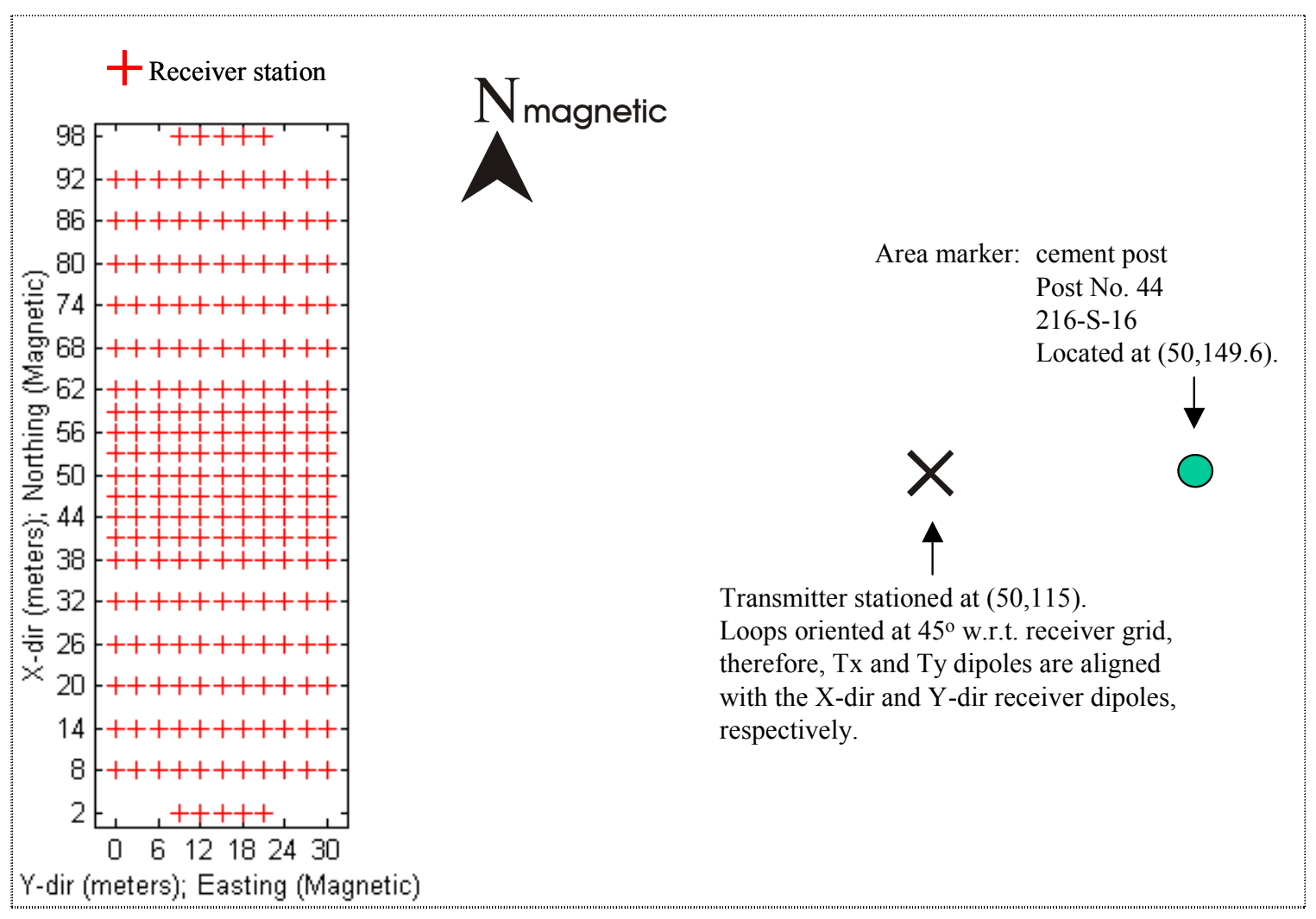

Figure 2: STRATAGEM survey layout.

Table 1: Transmitter frequencies

\begin{tabular}{|c|c|}
\hline Number & Frequency $(\mathrm{Hz})$ \\
\hline 1 & 1030 \\
2 & 1260 \\
3 & 1950 \\
4 & 2500 \\
5 & 2800 \\
6 & 3630 \\
7 & 5300 \\
8 & 6950 \\
9 & 11750 \\
10 & 15500 \\
11 & 22900 \\
12 & 51240 \\
13 & 67600 \\
\hline
\end{tabular}




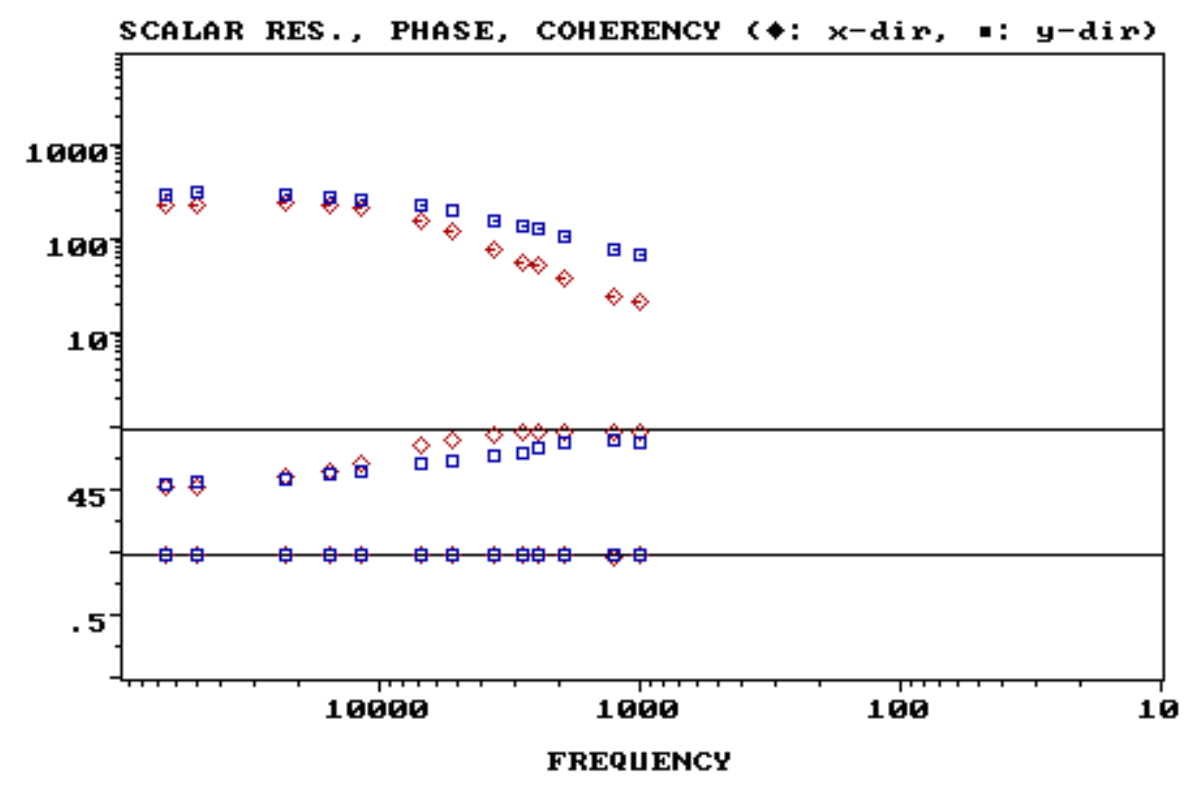

Figure 3: Data from station 23. Plots show scalar resistivity, phase and coherency. 